أحمد غانم حافظ أحمد

\title{
الحصانة الملكية
}

\section{أحد أثكال العلاقة بين الفرد والدولة فى مصر البطلمية}

فى ظل ظروف قاسية مات الإسكندر الأكبر وترك قواده الذين نقاسموا تركته فيما بينهم وآلت مصر إلى الوالى بطلميوس الذى سرعان ما أعلن نفسه ملكا على مصر لنتهد أرض الكنانة حقبة الإنة تاريخية جديدة سيطر فيها الملوك الجدد عليها.

ولا يخفى على باحث مدى حرص الملوك البطالمة على إحكام سيطرتهم على مستقرهم الجديد ذللك الحرص الذى نتى بـه تصرفاتهم التى سطرها المعاصرون لهم من المؤرخين وهو ما تتاولته أبحاث المهتمين الحديثين القيمة بالدراسة والتحليل.

وعلى الرغم مما قدمته الأبحاث السابقة . وهو كثير ـ من كثف عن الحقائق التاريخية التى تعود

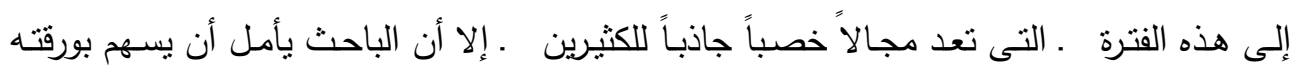
المتواضعة فى كثف جانباً من جوانب طبيعة العلاقة السياسية بين الحاكم ممثلا فى الملك البطلمي

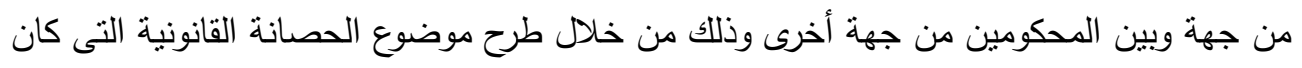

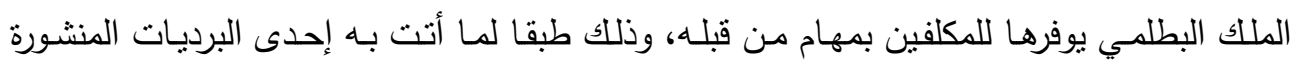

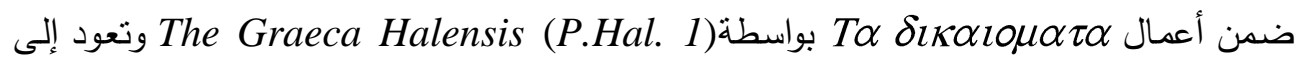
منتصف القرن الثالث ق •م.

وإذا كان البطالمة قد ساروا على نهج الإسكندر الأكبر خاصـة في مراحل إرساء الحكم الأولى،

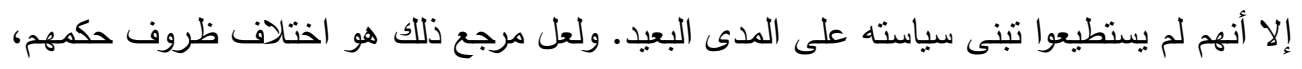

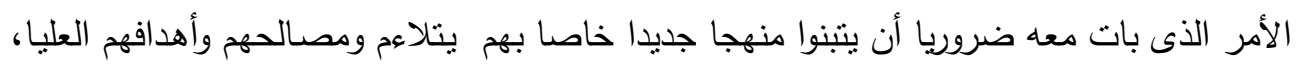

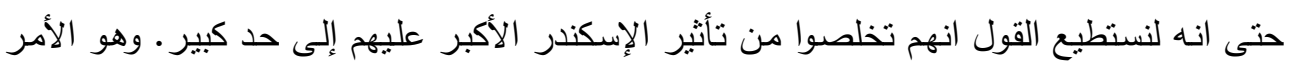

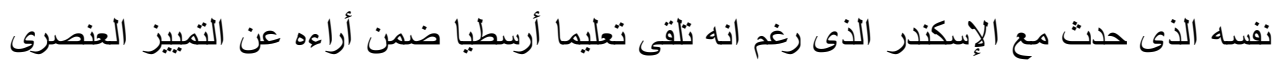




\section{الحصانة الملكية أحد أثكال العلاقة بين الفرد والدولة فى مصر البطلمية}

إلا انه تخلص من تلك النظرة الأرسطية العنصرية وهو ما ظهر فى زواجه من روكسانه Rhoxana (').Stageira ونتاجيرا

تعتمد الورقة بالأساس على ما ورد بإحدى الوثائق البردية المنشورة وسيقدم الباحث لها ترجمة

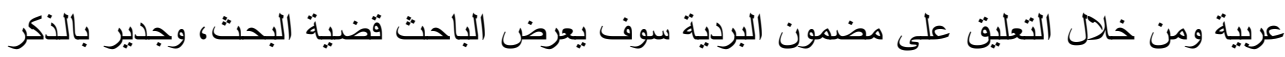

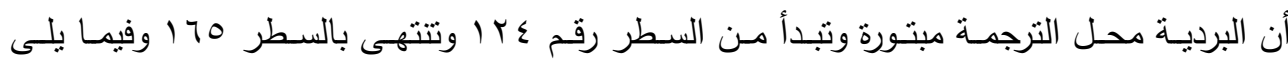

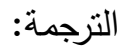

ل لا يتقدم أحد برفع دعاوى قضائية ضد أولئك المبعوثين من قبل الملك، ولا يتقدم أحد منهم

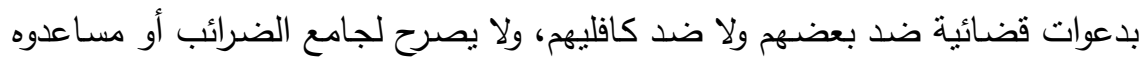

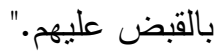

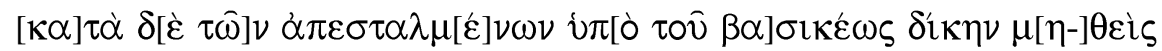

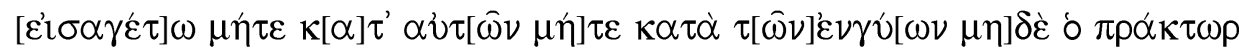

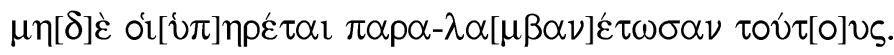

وبالمثل لا يتم تحريك دعاوى قضائية ضد ذوى الغائبين أو كافليه بخصوص أمور نزاعية.

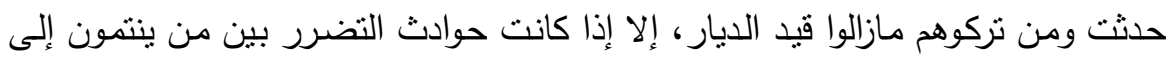

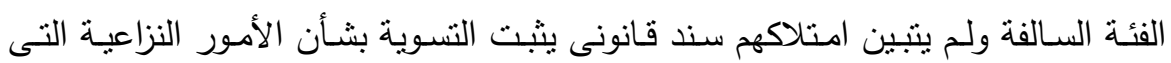
وقعت فى الوقت المذكور سلفا ففى هذه الحال يجب اللجوء إلى ساحة القضاء.

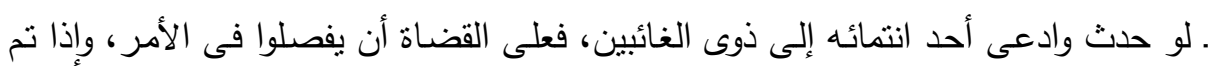
التعرف إليهم وإثبات حقيقة انتمائهم، وفى حال التحقق من مضمون شكواهي الهم وأنها حدثت وقت وجود الغائبون بالديار وانهم لا يملكون سند قانونى يثبت سلامة موقفهم القانونى فقى مئى

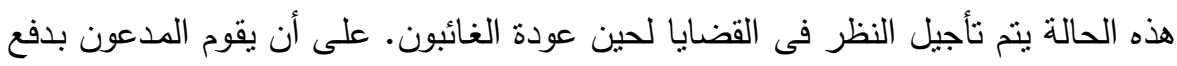
المصروفات والتى تقدر بقيمة العشر أو الواحد من الخمس عشرة.

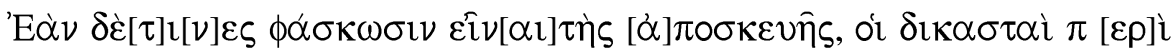

( (1) تتحدر كلا من روكسانه وستاجيرا من أصول فارسية ورأى البعض أن زواج الإسكندر بفارسيات بعد عملا رمزيا

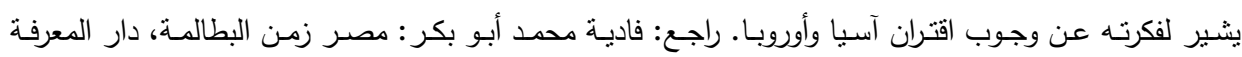

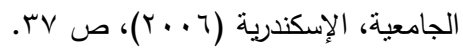




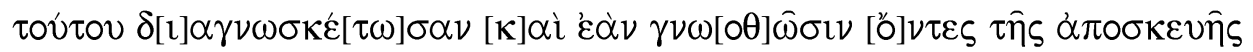

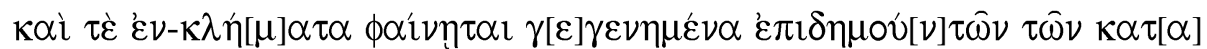

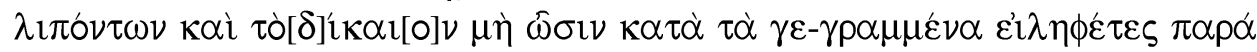

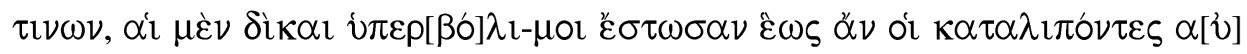
tov̀s

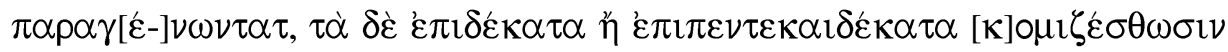
ól $\theta \dot{\varepsilon} v \tau \varepsilon \varsigma$.

$$
\begin{aligned}
& \text { • يتم الفصل فى كل القضايا التى أتُهم فيها ذوى الغائبين من قبل آخرين بأنهم قد آذوهم بعد } \\
& \text { رحيل الغائبين وكذلك تللك القضايا التى يتهم فيها هؤلاء أثخاص آخرين بأنهم آذوهم كل } \\
& \text { أمام المحكمة المختصة به. } \\
& \text { ـ لو أن من قام بتحريك الدعوى القضائية أرسل إلى الخدمة بتكليف من الملك قبل إجراء }
\end{aligned}
$$

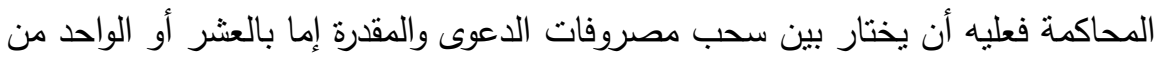

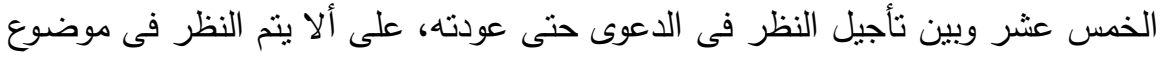

$$
\begin{aligned}
& \text { الدعوى إلا بعد إعادة دفع المصروفات. }
\end{aligned}
$$

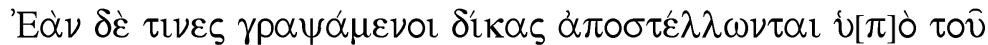

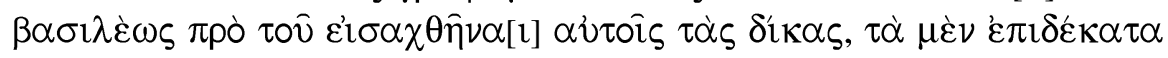

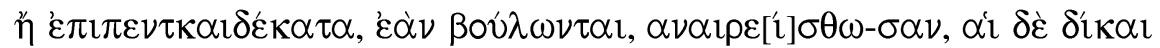

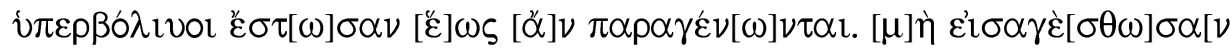

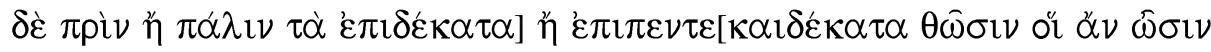
$\kappa \varepsilon \kappa о-] \mu 1 \sigma \mu \varepsilon \dot{\varepsilon} \mathrm{ol}$.

ـ إذا رفع المقيمون بالإسكندرية دعوات قضـائية وأرسلوا بعدها بتكليف من الملك للخدمـة وذلك قبل المثول أمسام القضـاء فيتم تأجيل دعواتهم بنفس الطريقة لحين عودتهم مرة

$$
\text { أخرى. }
$$

ـ الأفراد المقيدين بالخدمة العسكرية الذين سمح لهم بالتمتع بمواطنة الإسكندرية فى حال

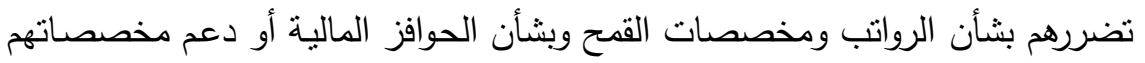
من القهـح إذا كان لهم خصوما أثناء الخدمـة من الحاصلين على المواطنة فعليهم أن 
يتقدموا بدعواتهم القضائية أمام محاكم الأجانب على أن ينت الفصل فيها طبقا لها ورد

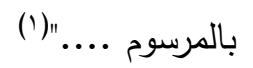

بدايـة من خـلال القراءة السـابقة لمضمون الوثيقة يلاحظ أنها تعبر عن شكل من التظظيمات

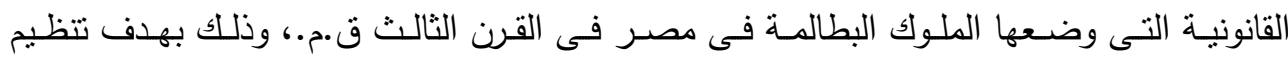
العلاقات بين أفراد المجتمع على اختلاف الجنسيات التى سكنته فى تلك الفترة من جهة، وبهدف تحديد العلاقة بينهم كملوك حكام وبين المواطنين كمحكومين فى إطار معلن وواضح. وليس المقصود هنا بلفظة "المواطنين" كل المواطنين من أفراد المجتمع على اختلاف أدوارهم

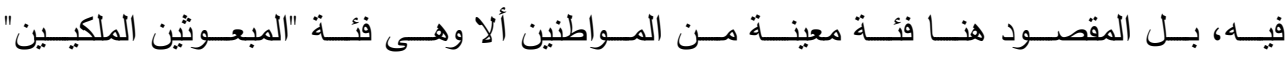

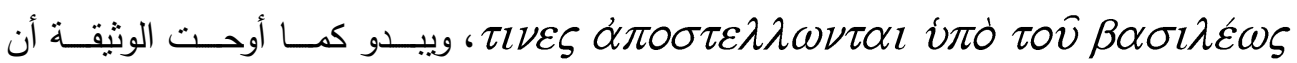

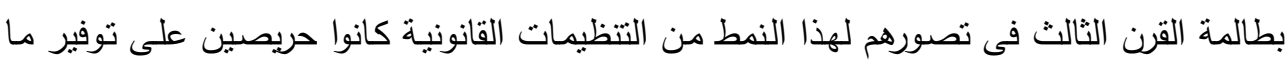
يضمن استقرار أوضاع مبعوثيهم وبالتالى استقرار العلاقة نسبيا بينهم بصفتهم ممنلين للاولة وبين هؤلاء المبعوثين بوصفهم فئة هامة من المواطنين فى المجتمع.

ركزت الوثثقة على طبيعة الوضع القانونى لقضايا حالات بعينها من المبعوثين الملكيين وغيرهم

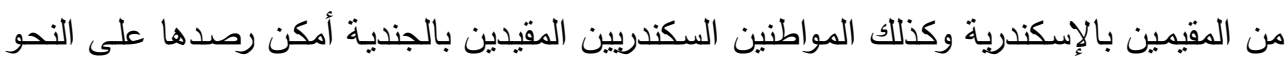
النالى : - n 1 ـ الوضع القانونى للمبعوثين من قبل الملك فى مهام.

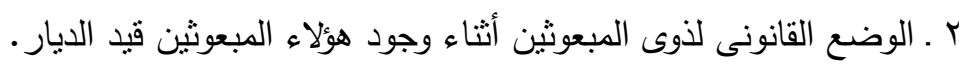

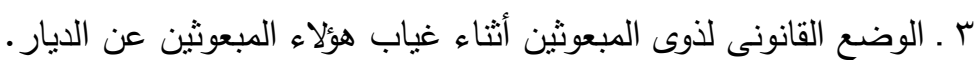

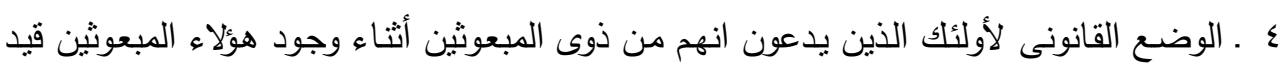
الديار . ه ـ الوضع القانونى لدعاوى المبعوثين القضائية التي أقاموها قبل تكليفهم.

(1) Hunt A. S. \& Edgar C. C., Select Papyri Official Documents with An English Translation, Harvard University Press, L.C.L., Vol. II, (1995), no. 201. P. Hal. 1. ll. 124-165. 
7 ـ الوضع القانونى لقضايا المقيمين بالإسكندرية التى أقاموها قبل تكليفهم. V ـ الوضع القانونى للمقيدين بالخدمة العسكرية من حملة المواطنة السكندرية.

وفى هذا الصدد نجد الوثثقة تتحدث فى بدايتها عن قرار لفت نظر الباحث ألا وهو تمتع

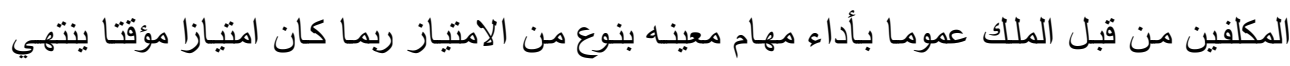

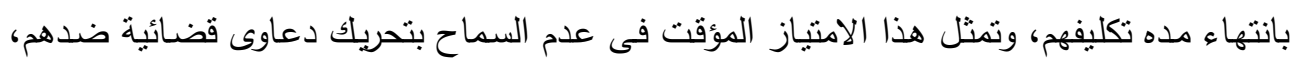

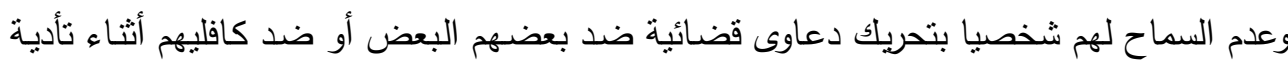
المهام المنوطة بهم، وعدم السماح لجامعى الضرائب ومساعدوهم بالقبض عليهم. ولا يتضـح من صـيغة القرار المذكور لا جنسية هؤلاء المبعوثين ولا طبيعـة المهام المبعوثين

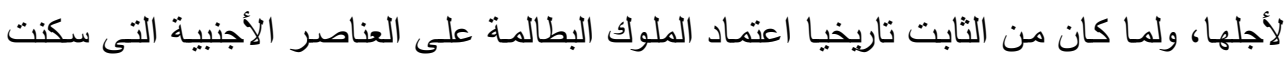

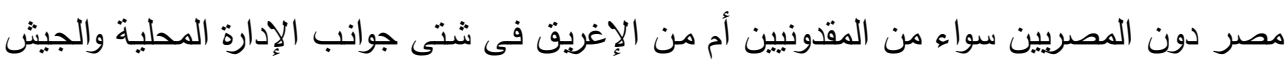

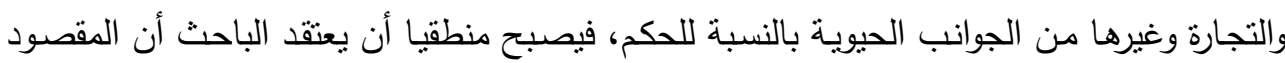

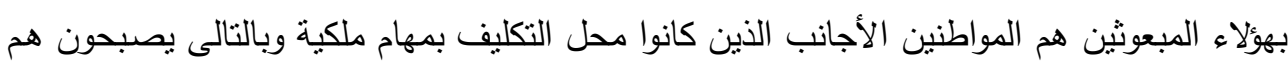

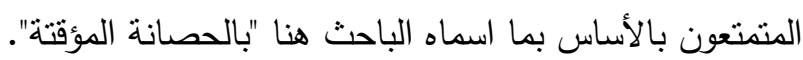




\section{أولا: الأثر الاجتماعى لحصانة المبعوثين الملكيين}

إن الحديث عن حصانة المبعوثين الملكيين يثير فى الواقع عدد من التساؤلات الأول: هو من هم المبعوثين الملكيين وكيف كان يتم اختيارهم؟، الثانى هو ما هى أهمية هؤلاء المبعوثين لدي الإدارة

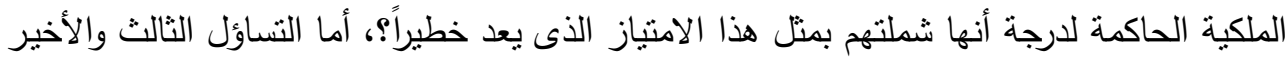

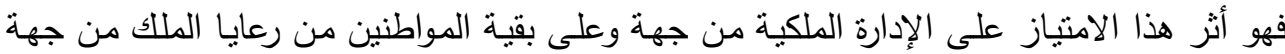

بالنسبة للمبعوثين الملكيين فيبدوا أن طبيعة الظروف السياسية التى واجهت البطالمة في مصر قد فرضت عليهم تكليف الأجانب الذين حرص البطالمة منذ بطلميوس الأول على استقدامهم إلى

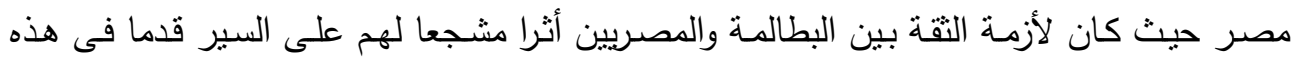

وقد أدى زيادة اعنمـاد الملوك البطالمـة على موظفيهم من الأجانب فى شتى جوانب الحيـاة السياسية والإدارية والعسكرية إلى تمييزهم بالضرورة عن المصريين، هذا التمييز الذى كان منهجا ثابتا انتهجه البطالمة قبل رفح VIV ق. V.م، ولا يبدو انه تغير كثيرا بعدها رغم تغير نظرة البطالمة

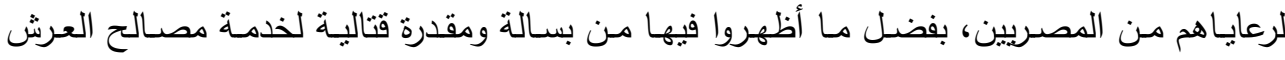

$$
\text { الملكى البطلمي ضد أعدائهم من السيليوقين. }
$$

ظل إذن الاعتماد على الأجانب فى مختلف مجالات الإدارة المحلية وكال لهم البطالمة العديد من الوظائف والمهام وحتى فى ظل هذه السياسة الرسمية التى اتبعها الملوك البطالمة لم تكن هناك الك التحات المسـاواة الطبيعيـة بين كل الأجانب، حيث زاد اعتمـاد البطالمـة على بنى جلدتهم من المقدونيين

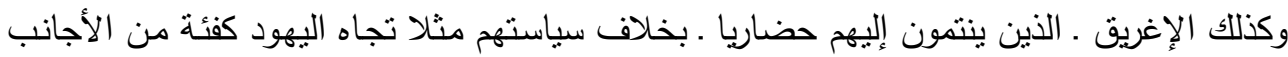
فى مصر ، وعلى سبيل المثال لا الحصر فبالإضافة لامتياز اختيارهم لثنل وظائف هامة، تركت

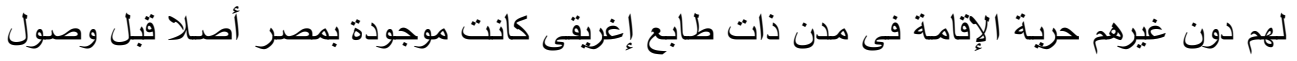

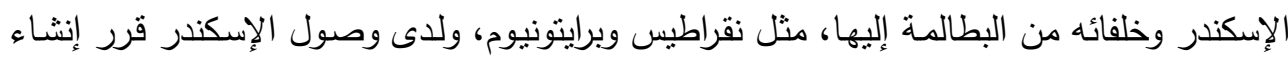

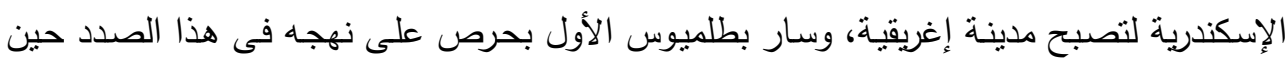
قرر إقامة مدينة بطلمية وبالمثل فقد كان الملك بطلميوس الثنانى حريصا على استرضاء الإغريق 


\section{الحصانة الملكية أحد أثكال العلاقة بين الفرد والدولة فى مصر البطلمية}

وهو ما يظهر فى حادثة زواجه من شقيقته أرسينوى الثانية حيث عرفا معا باسم الإلهين الأخوين

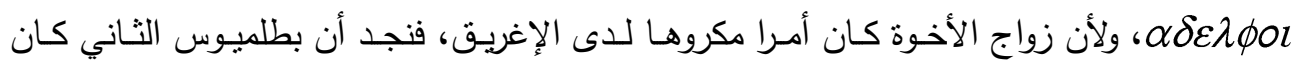

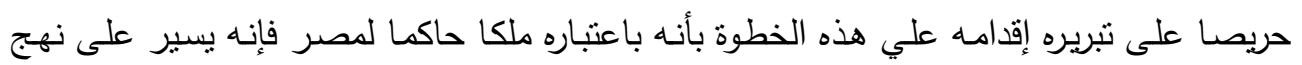
الفراعنة الذين درجوا على الزواج من شقيقاتهم. (')

وإذا أمعنا التفكير فى بنود القرار السـابق ذكره بشأن عدم السماح بمقاضـاة أى من المبعوثين

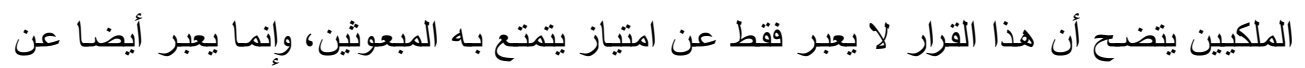

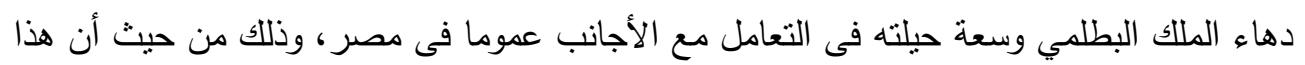

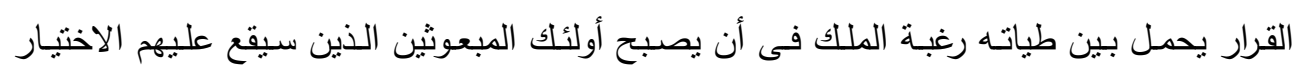

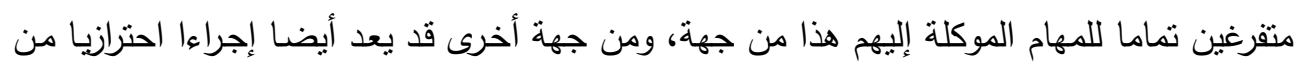

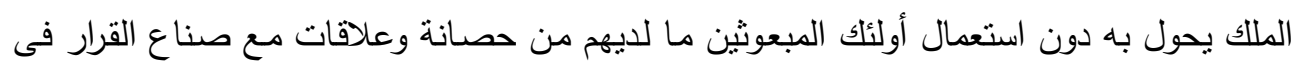
فض منازعاتهم ربما على نحو يحقق صالحهم بالأساس دون النظر للمجرى العدالة.

كذلك لقد منع القرار أن يتقدم أولئك المبعوثين بدعاوى قضائية ضد بعضهم بعضا وذلك أثناء

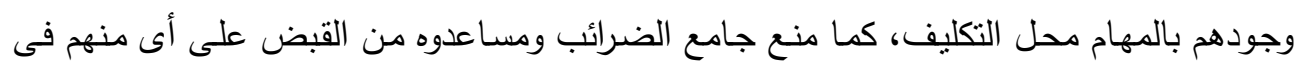
حال وجود ضرورة لذلك، ويفهم من ذلك أن الملك البطلمي أطلق لهؤلاء المبعوثين عنان الحرية بما

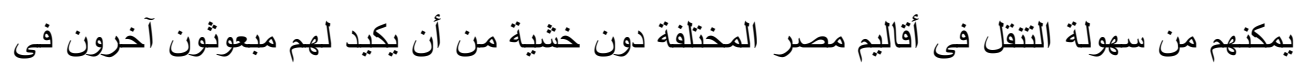

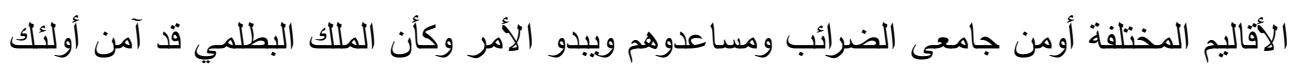
المبعوثين على أنفسهم بهدف تحقيق افضل النتائج فى مهام كل منهم.

ولن يخوض الباحث فى سياسة التمييز ذاتها فهى سياسة معروفة عن البطالمة فى مصر ، ولكنه

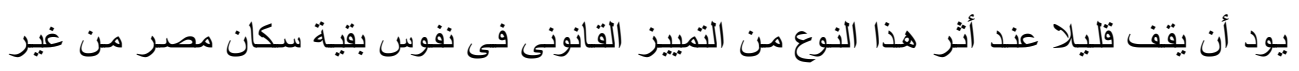

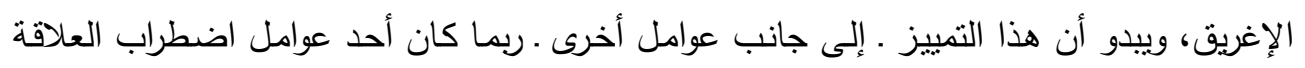

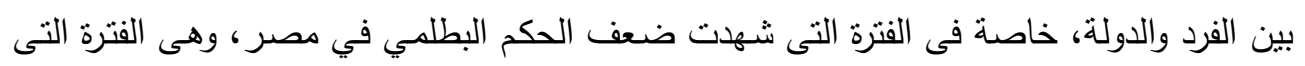

(1) أبو اليسر فرح: تاريخ مصر فى عصرى البطالمة والرومان، عين للاراسات والبحوث الإنسانية والاجتماعية، القاهرة

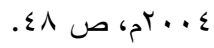




\section{الحصانة الملكية أحد أشكال العلاقة بين الفرد والدولة فى مصر البطلمية}

اصبح فيها الملوك البطالمة غير قادرين على السيطرة على بعض مقدرات أمور دولتهم، مدا جعلهم

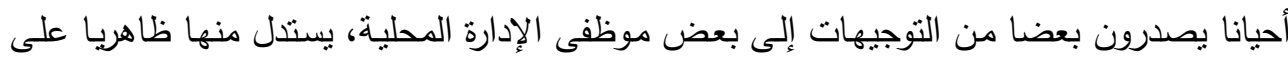

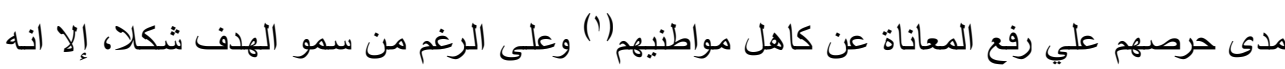
لا يخلو فى مضمونه من حرص الملوك البطالمة على تحقيق غايات تصب فيى النهاية فى صالح

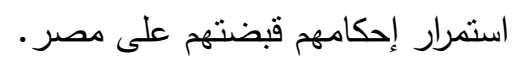
وتجدر الإثـارة هنا إلى ماهية العلاقة بين الفرد والدولة فى مصر البطلمية، وكيف أنها كانت علاقة تتصف بالتذبذب إذ كانت مرهونة بعدة أمور أولها: قوة الحاكم أو ضعفه ثانيها: مدى نضورجه

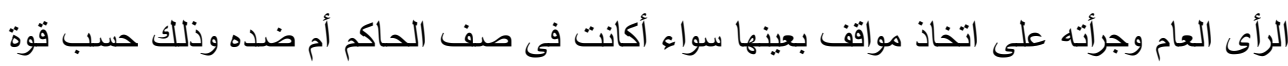
الحاكم أو ضعفه. وذللك رغم الحصانة الملكية التى أحاط بها الملك البطلمي نفسه وموظفيه حيث ضرب على شخصده هالة مقدسة بهدف تمكينه من إحكام قبضته على رعاياه وهو ما يتضـح جليا

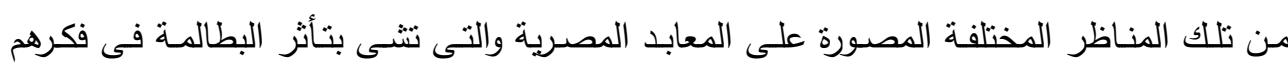

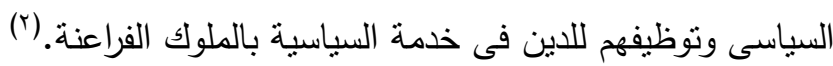
وربما كانت الحصانة الملكية التى تمتع بها الملك البطلمي والتي منح بعض موظفيه حق التمتع

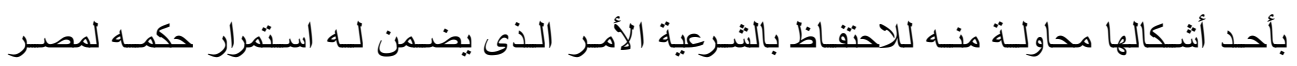

(1) Hunt A. S. \& Edgar C. C., op. cit., No. 204.

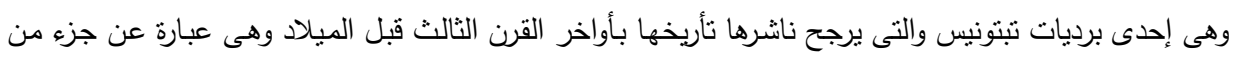

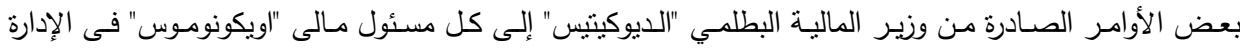

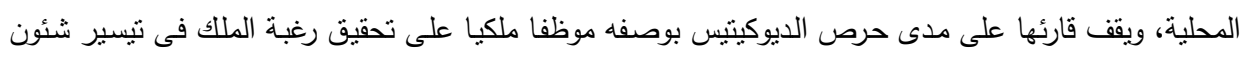

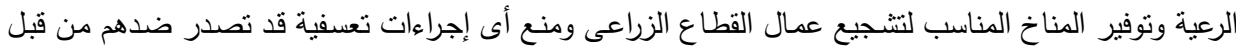

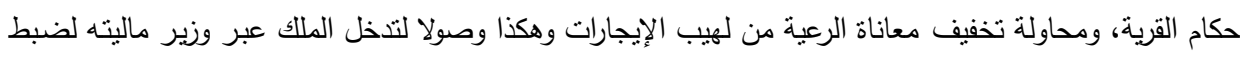
أسعار السلع فى الأسواق.

(2) Gunther Holbl., A History of the Ptolemaic Empire, London, (2001), p. 76-98.

حيث يناقش فكرة الملكية وتوظيف الدين لخدمة السياسة موضحاً مدى تأثير الملوك البطالمة بالإسكندر الأكبر فى

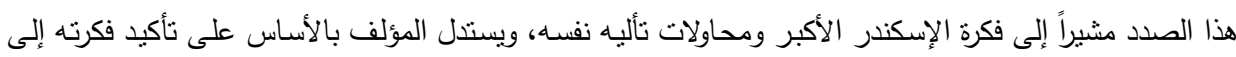

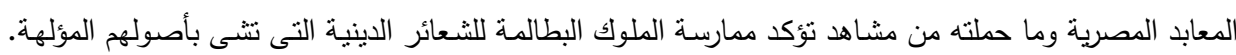




\section{الحصانة الملكية أحد أشكال العلاقة بين الفرد والدولة فى مصر البطلمية}

والمصريين، ويبدو أن هذه المحاولة جاءت نتيجة شعور مـا بافتقاده شرعية الحكم، والسؤال الذى

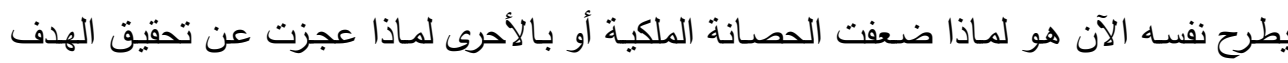
منها بالنسبة للملوك البطالمة على مدار تاريخهم فى مصر ، في حين أنها كانت عقارا شافيا لمعظم

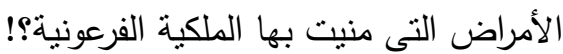

وفيما يخص قصور النظام الملكى البطلمي فى مصر رغم انه نظام اقتبسه البطالمة من الفراعنة

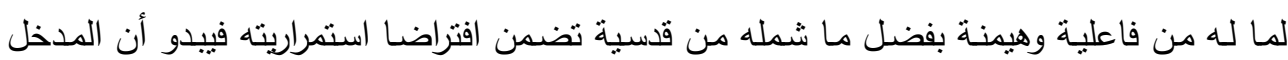

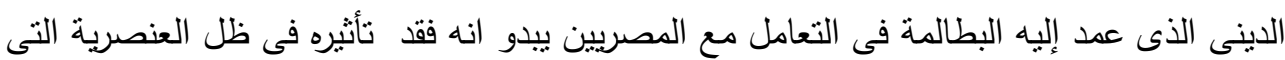

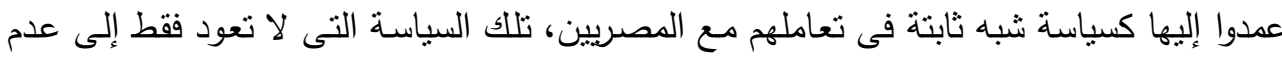

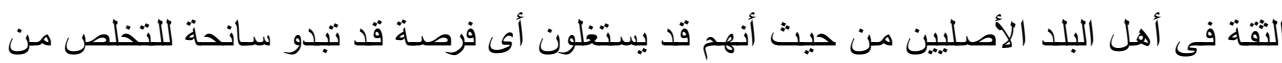
الحكم البطلمى، ولكنها تعود أيضا إلى فلسفة قديمة زرعها المعلم الأول فى عقول الإغريق وسار

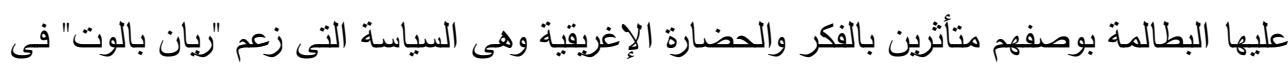
خضم بحثه فى الفكر السياسى اليونانى عموما والهللينستي على وجـه الخصـوص أن الإسكندر الأكبر قد تجاوزها لأخرى افضل وهى فلسفة "وحدة الجنس البشرى".(')

ويرى البعض أن فلسفة "وحدة الجنس البشرى" التى تبناهـا الإسكندر الأكبر واعتمد عليها فى ردي

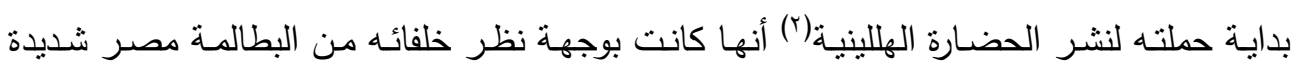

(1) Balot Ryan K., The Greek Political Thought, Blackwell Publishing, (2006), $1^{\text {st }}$ published, p. 267.

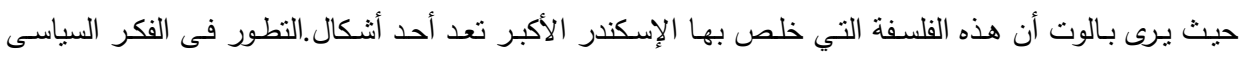
اليونانى الموروث الذى وضع أساسه أرسطو حيث أكد على أن الإغريق هم الأقدر على إدارة شئون الحكم والسياسة

$$
\text { وأن غيرهم من البرابرة ol B }
$$

L.C.L.: Aristotle, Politics, books vii-iix

$$
\text { وراجع التعليقات القيمة التي وردث بشأن هذه القضية عند: }
$$

Taylor C. C. W., "Politics", Barnes J., ed., The Cambridge Companion to Aristotle, Cambridge, Cambridge University Press, (1995), pp. 239-41.

Balot, Aristotle's Critique of Phaleas: Justice, Equality, and Pleonexia" Hermes 129 .1, (2001), pp. 32-44.

(2) Bosworth A. B. and Baynham E. J., Alexander the Great in Fact and Fiction, Oxford, Oxford University Press, $1^{\text {st }}$ published in paperback, (2002), p. 107. 
المثالية لأن ينم تطبيقها أثناء إدارتهم الملكية لمصر (') ويتفق الباحث إلي حد كبير مع هذا الرأى لا

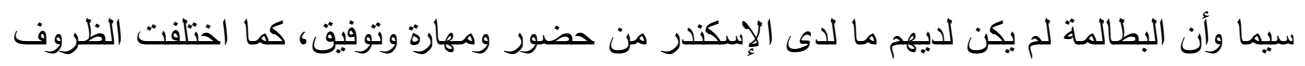
التى عاشوا فيها وسط المصريين عن تلاك التي عاصرها الإسكندر معهم.

هكذا يتضـح للقارئ إجمالا أن العنصرية الصارخة التى عومل بها المصريين من قبل حكامهم

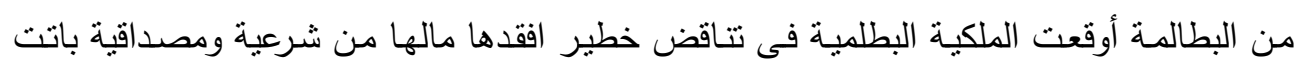

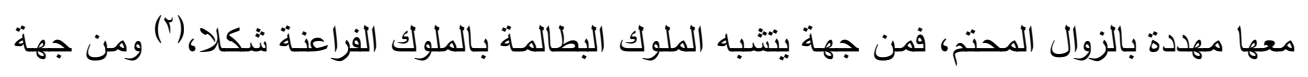

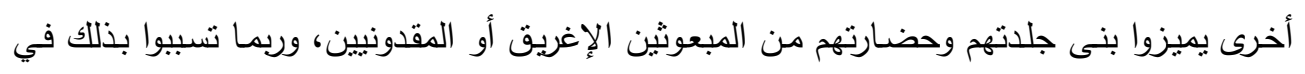

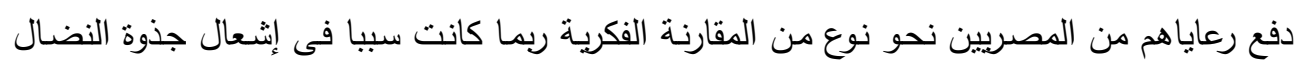

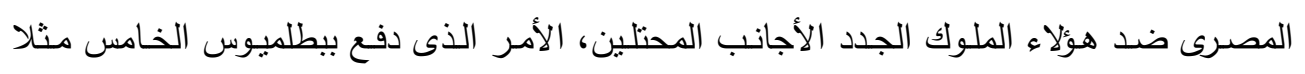

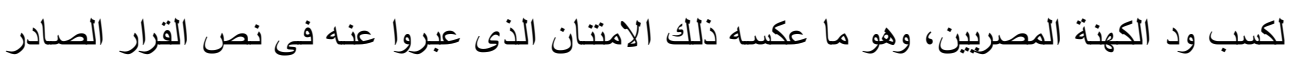

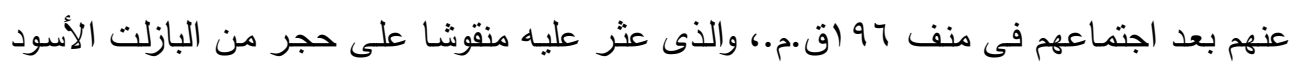

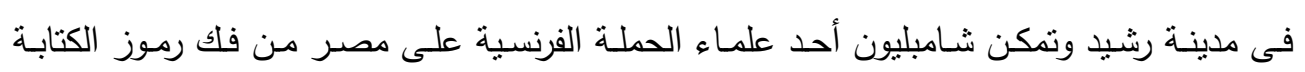

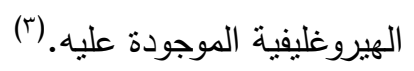

عموما فمن خلال ما ورد بالوثيقة يمكن أيضا إدراك ما كان لمثل هؤلاء المبعوثين الملكيين من

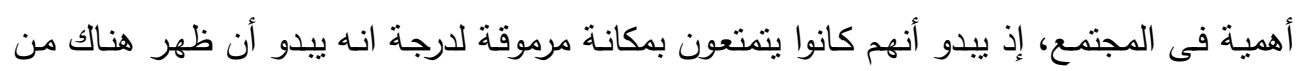

حيث يذكر مايكل فلاور فى مقاله الذى نشره فى إطار العمل السابق مباشرة بعنوان "الإسكندر والروح الجمعية الهللينية" أن كاليسشيس Callisthenes من أولينثو يعد أخيل آخر.

( ) رأى تفضل بـه أ.د/ محمد السيد عبد الغنى أستاذ التاريخ والحضارة اليونانيـة والرومانيـة بآداب الإسكندرية أثناء مناقثات دارت بين سيادته والباحث وهو بصدد الإنتهاء من صيغة البحث النهائية.

(2) Rostovtzeff. M., Social and Economic History of the Hellenistic World, London, (1952), pp. 267-8.

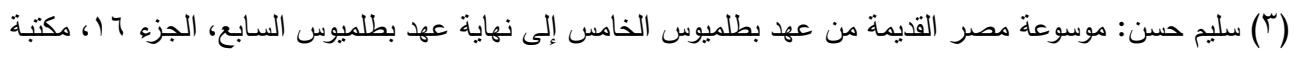

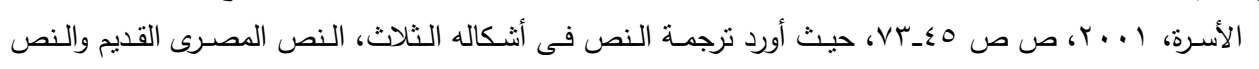

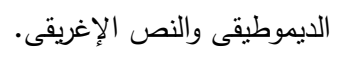


يدعون انتسابهم لهؤلاء المبعوثين ربما كى يتمكنوا من التمتع ببعض الامتيازات التى أوقفتها الدولة

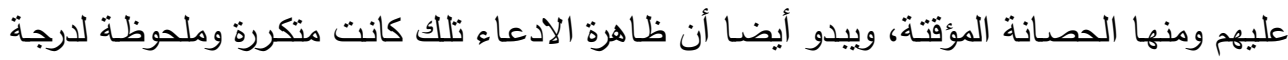
احتاج معها الأمر اللجوء للقضاء لإثبات حقيقة الادعاء من عدمه.

ويمكن بالمتل من خلال الوثيقة الوقوف على وضع المبعوثين من المقيمين فى مدينة الإسكندرية حيث ورد بالوثثقة ما يقضى بضرورة تأجيل دعواهم القضائية لحين عودتهم من المهوة التى كلفهم

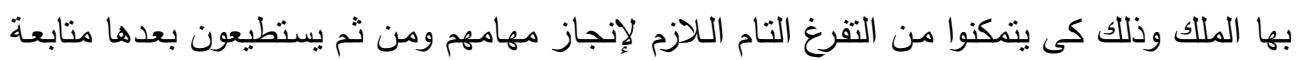
دعواهم القضائية وما يتطلبه ذلك من حضور للجلسات وتقديم أوراق الدفاع المطلوبة. 
ثانيا: الأثر السياسى لحصانة المبعوثين الملكيين

يقصد الباحث بالأثز السياسى لحصانة المبعوثين الملكية توضيح ما ترتب على تلك الحصانة من نتائج إيجابية أو سلبية تأثرت بها السياسة البطلمية فى مصر فى محاولة لتقيبم أداء من تمتعوا بهذا الامتياز من قبل الملوك البطالمة.

بدايـة يمكن القول بـأن الامتيـازات التى أوقفها الملك البطلمى على مبعوثيـه ومنهـا الحصـانة

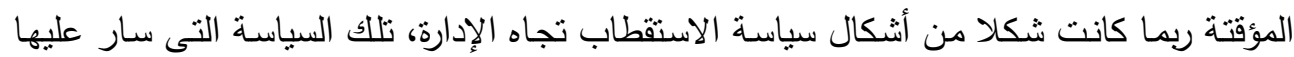

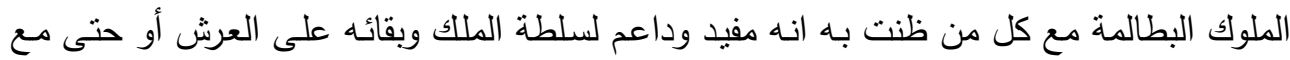
من كان يخشى جانبهم على العرش.

وإذا كانت الحصانة الملكية قد منحت الملك البطلمى ذاته الفرصسة للاستئنار بالسلطة المطلقة

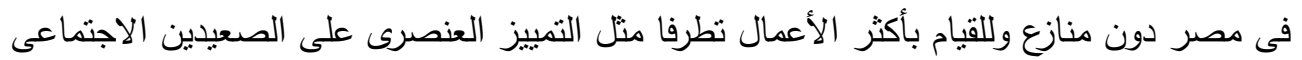
والسياسى فهى بالمثل منحت الفرصة الأكبر لموظفى الملك ـ بمن فيهم مبعوثيه ـ للانحراف وهنا

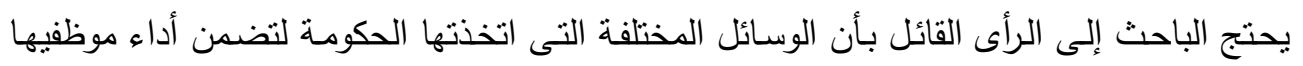

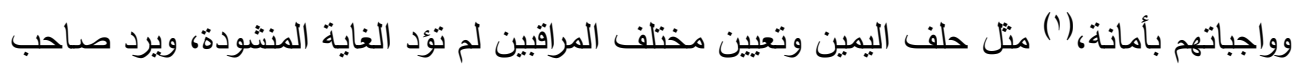
هذا الرأى تللك الحقيقة إلى عوامل ثلاثة، وهى: بهى: أولا: السلطة المطلقة التي كان الموظفون يتمتعون بها على شعب أذله الحاكم الأجنبى. ثانيا: المسئولية الملقاة على عاتقهم عن دخل الملك ومصالحه.

( (1) إبراهيم نصحى: تاريخ مصر في عصر البطالهة، الجزء الثالث، الطبعة السادة منقحة، مكتبة الأنجلو الدصرية،

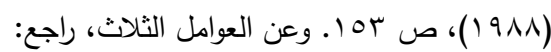

Bouche-Leclercq, Histoire des Lagides, 4 vols., Paris, (1903-1907), vol. III, p. 394. عن حالات الفساد الإدارى لبعض موظفى الإدارة الملكية أحيل القارئ لبعض الأمتلـة التى وردت لدى الدكتور

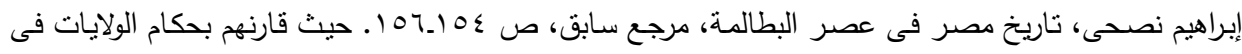

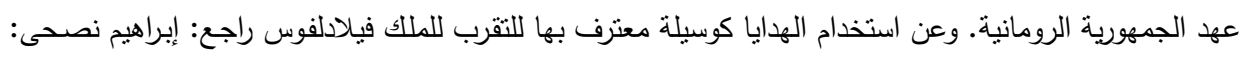

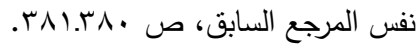


ثالثا: الهدايا التى كانوا يقدمونها للمسئولين عند تعينهم وتجديد مدة خدمتهم، حيث كانوا يستردون ما أنفقوه باستغلال نفوذهم بشتى الطرق.

هنا يود الباحث أن يعلق على الرأى السابق حيث يري أن حلف اليمين وتعيين المراقبين على

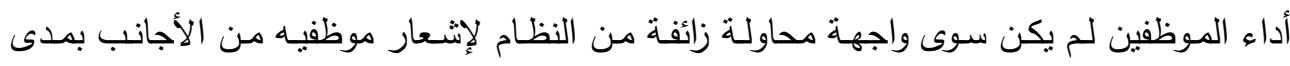
حاجته إليهم، خالفت بطبيعة الحال أسلوب الحكم الملكي البطلمي الذى كانت المركزية أساسا لـه.

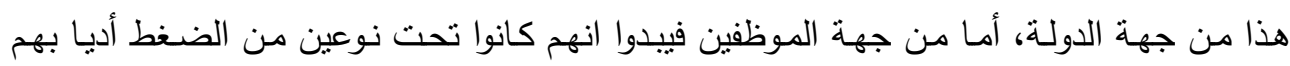
للانحراف وسوء استغلال السلطة. أمسا النوع الأول: ويتمثنل فى رغبـة البعض منهم فى إبداء تفانيه في خدمـة الملك وحرصسه على في

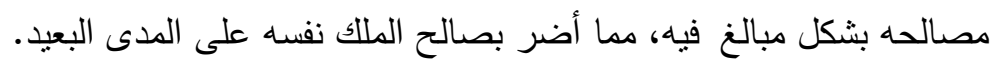

ويتمثل النوع الثانى: من الضغط فى سياسة الملك البطلمي التى انتهجها فى تعيينه لموظفيه التى

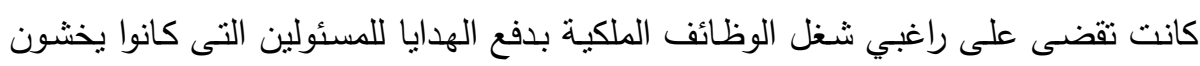

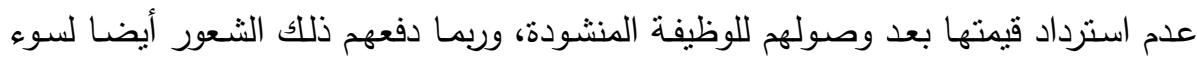
استغلال صلاحياتهم التى منحت لهم بالمقابل.

وإذا كانت الوثيقة قد تحدثت عن وضـع نوع من المبعوثين الملكيين ولم تحدد طبيعة المهام

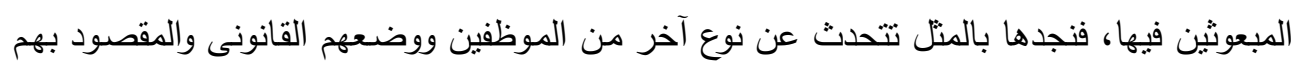

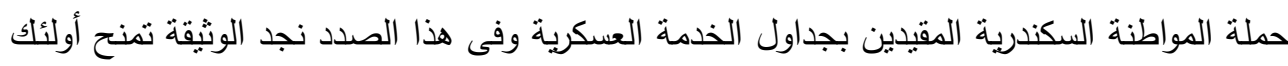

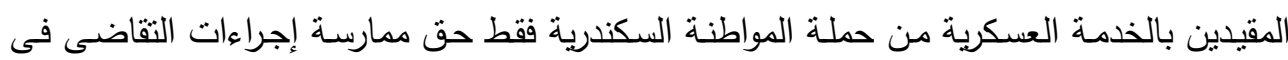
حال تضررهم بشأن الرواتب ومخصصاتهم من القمح فى حال رغبتهم دعم حوافزهم المالية أو دعم

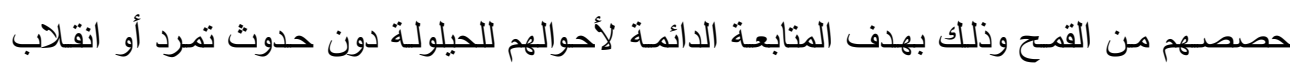

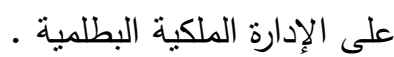

وفى نفس السياق نجد أن الملك البطلمي نفسه كان حريصا على نأكيد ذلك النوع من الحصانة

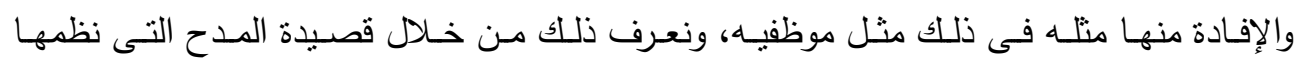
ثيوكريتوس السيراكوزى فى شخص بطلميوس الثانى فيلادلفوس، حيث حرص فيها على إظهار 


\section{الحصانة الملكية أحد أشكال العلاقة بين الفرد والدولة فى مصر البطلمية}

محاسن مليكه ومنها إرضائه للآلهة، الأمر الذى انعكس على الرخاء والسلام والقوة التى تمتع بها عصره، (') فهو يعترف بحقيقة هامة وهى أن زيوس بن كرونوس يولى عنايته للملوك المؤلهين.

وعلى الرغم من أن الباحث يسلم بحقيقة ثيوكريتوس وكونه شـاعرا من شعراء البلاط الملكى (r)

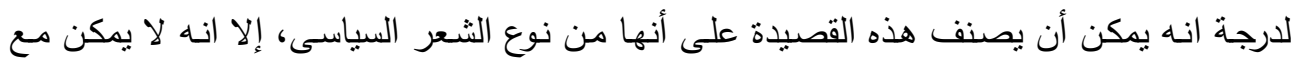

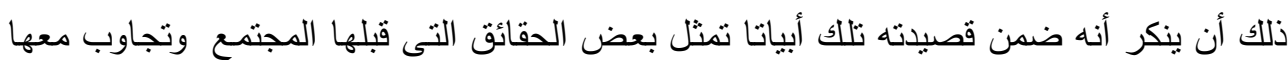
كجمهور، ومنها أن الملك بطلميوس الثانى بوصفه أحد الملوك البطالمة كان حريصـا على ثأكيد

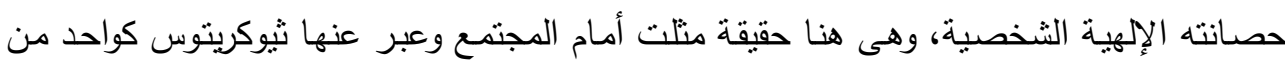
فنانيه.

وفى هذا الصدد يبدو أن الملوك البطالمة ومنهم بطلميوس الثانى على سبيل المثال لم يكتفوا

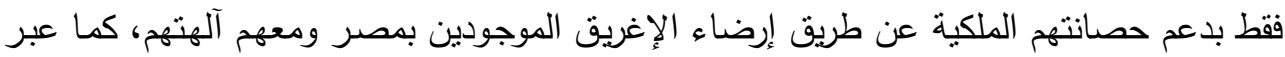

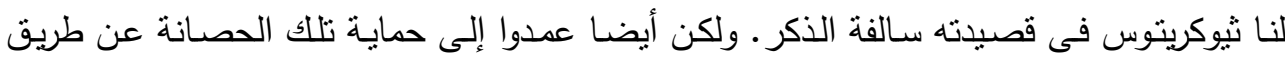

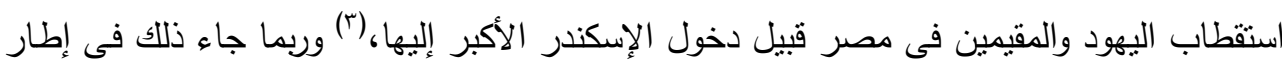
حرص الملوك البطالمـة على عدم إثارة مشاعر سكان مصر من الأجانب وبخاصـة اليهود الذين الذين

(1) Theocritus, XVII, 73-130.; cf. Austin M. M., The Hellenistic World From Alexander to the Roman Conquest, A selection of ancient sources in translation, $2^{\text {nd }}$ augmented ed., Cambridge University Press, (2006), p. 449.

(r) عن علاقة الملوك البطالمة بشعراء البلاط وكيف وظفوهم للاعاية السياسية لحكمه فى عصور القوة، راجع: Griffiths F. T., Theocritus at Court, Leyden, (1979), pp. 71-82.

Fraser P. M., Ptolemaic Alexandria, vol. I, Oxford , (1972), p. 194f., 232, $666 f$.

$$
\text { (T) عن أثكال الاسترضاء البطلمى لليهود فى مصر راجع خطاب اريستياس إلى فيلوكراتيس والمنشور بطبعة: }
$$

Hadas M., New York, (1951), I. 9-11; V. 35-40.

حيث يعدد فيه الملك فيلادلفوس الامنيازات المنوحة من أبيه سوتير ومنه شخصيا لليهود، ومنها تحرير اكثر من

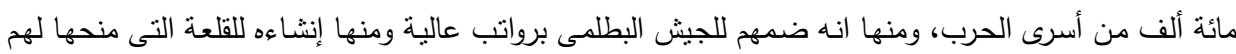

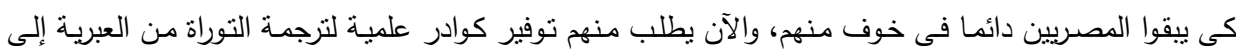
اليونانية كى تصبح بجوار بقية الكتب الملكية ويطلب من حبرهم الأعظم إليعازر

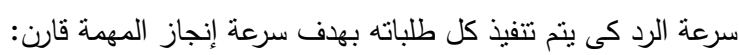

Austin M. M., op.cit., p. 459. 
مارسوا فى الإسكندرية نشاطا اقتصاديا وحرصوا كذللك على دخول معترك الحياة السياسية فى

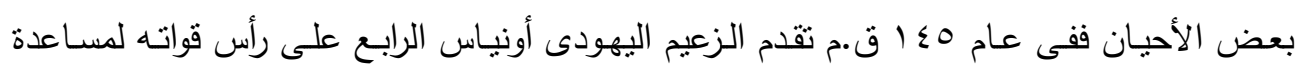

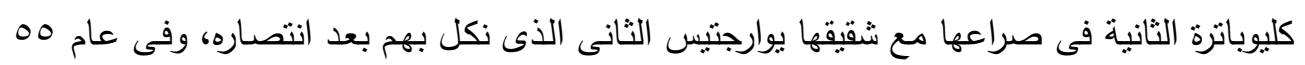
ق.م. ساعد اليهود جابينيوس والى سوريا الرومانى الذى قام بغزو مصر لإعادة بطلميوس الزئي الزمار إلى العرش. (1)

مما سبق بستطيع القارئ أن بدرك أن الحصانة الملكية النى أحاط بها الملوك البطالمة أنفسهم

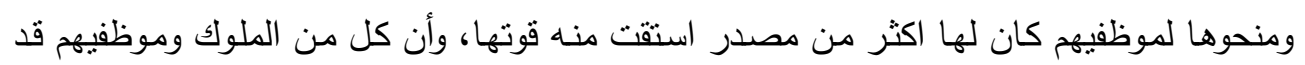

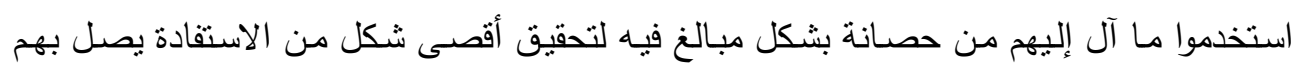
لدعم سيطرتهم الكاملة على المجتمع المصرى بكل فئاته.

وفى تقييم الباحث لأثر حصسانة الملك ومبعوثيهـ السياسبة علي الصسيد السباسى فى مصر

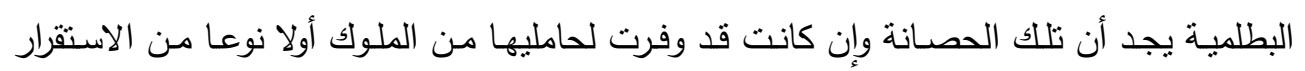
المبدئى فى قيادتهم لرعاياهم من المصرين الذين اعتادوا متل هذا النمط من الحكم السياسي إلا أنها اضطرتهم فى الوقت ذاته لتبرير موقفهم ذلك أمام بقية رعاياهم من الإغريق وهى الفئة التى أولوها

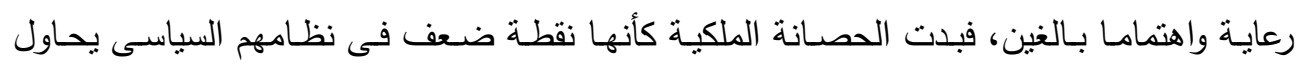

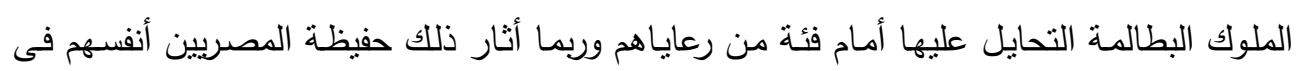

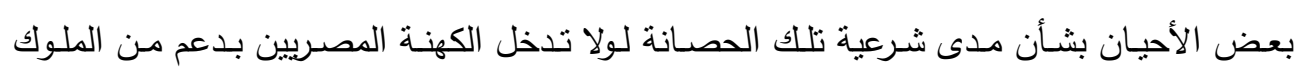

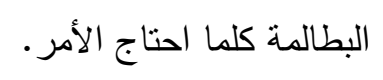

وهـا هـو فرانسـواز دونـان يصـف العبـادة الملكيـة على إنها وسـيلة اسـتخدمها البطالمـة لـدعم حصانتهم للدى رعاياهم من الإغريق في مصر حيث تحدث دنان عنها بوصفها وسيلة فعالـة بالنسبة

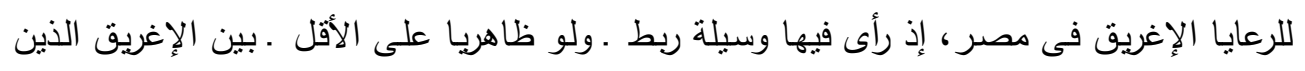

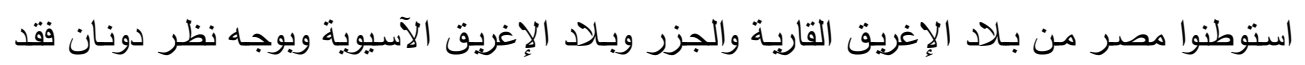

(1) أبو اليسر فرح: ناريخ مصر فى عصرى البطالمة والرومان، مرجع سابق، ص •11. 


\section{الحصانة الملكية أحد أثكال العلاقة بين الفرد والدولة فى مصر البطلمية}

كانت وسيلة ضمن بها الملوك البطالمة تقديس السلطة التى لم تكن فى بداية الأمر إلا سلطة أحد

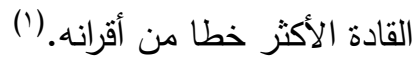

وقد نفى دونـان عن الملوك البطالمـة استعمال العبادة الملكيـة بهدف التأثنر علي المصريين

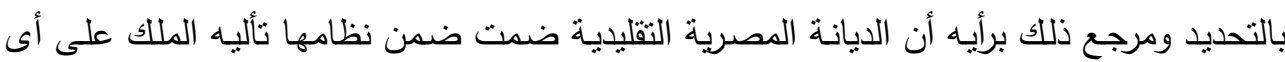
حال بدليل وجود مكان داخل المعابد المصرية ذاتها خصص لتماثيل الملوك ويعبدون فيه على الطريقة المصرية كأجراء منهجى بطبق منذ عصر قرار منف عام 97 اق .م.

هكذا ومما سبق يتضـح أن الوثيقة محل الدراسـة قد تحدثت عن الوضـع القانوني لنوعين من الموظفين وهما المبعوثين الملكيين والمقيدين بالجندية من المقيمين بالإسكندرية من حملة المواطنة

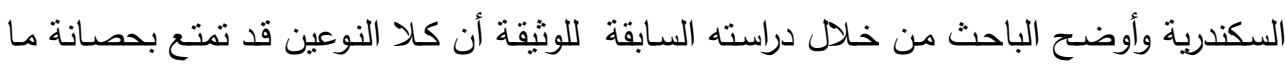
ارتبطت بطبيعة الدور الذى يقوم بـه كل منهم فما كان محظورا على أحدهم كان مسموحا للآخر وربما كان ذلك مقصودا من قبل النظام الحاكم كى يتمكن من الإفادة القصوى من كل أدواته وفق المتغيرات السياسية التى كانت تعن له.

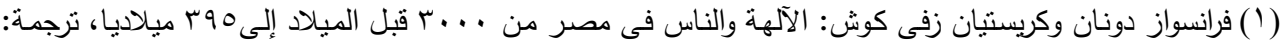

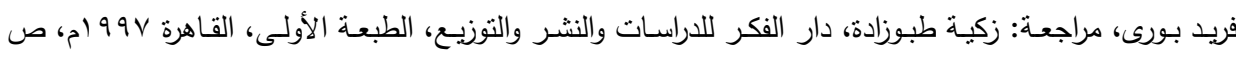




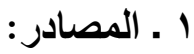

- Aristotles, Politics, Loeb.

- Hunt A. S. \& Edgar C. C., Select Papyri Official Documents with An English translation, Harvard University Press, L.C.L., vol. II, (1995).

- Theocritus, L.C.L.

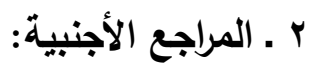

- Austin M.M., The Hellenistic World From Alexander to the Roman Conquest, A selection of ancient sources in translation, $2^{\text {nd }}$ augmented ed., Cambridge University press, (2006).

- Balot Ryan K., The Greek Political Thought, Blackwell Publishing, (2006).

- ---------------., ”Aristotle's Critique of Phaleas: Justice, Equality, and Pleonexia" Hermes, 129, I, (2001).

- Bosthworth A. B. \& Baynham E. J., Alexander the Great In Fact and Fiction, Oxford, oxford University press, $1^{\text {st }}$ published in Paperback, (2002).

- Bouche-Leclercq, Histoire des Lagides, 4 vols., Paris, (1903-1907).

- Fraser P. M., Ptolemaic Alexandria, vol. 1, Oxford, (1972).

- Gunther Holbl, A History of The Ptolemaic Empire, Routledge, (2001).

- Griffiths F. T., Theocritus at Court, Leyden, (1979).

- Rostovtzeff M., Social and Economic History of the Hellenistic World, London, (1952).

- Taylor C. C. W., "Politics", Barnes J., ed., The Cambridge Companion to Aristotle, Cambridge University press, (1995). 


\section{r ـ المراجع العربية والمعربية}

ـ إبراهيم نصحى: تاريخ مصر فى عصر البطالمة، الجزء الثالث، الطبعة السادسة منقحة، مكتبـة

$$
\text { الأنجلو المصرية (911 (191). }
$$

ـ أبو البسر فرح: تاريخ مصر فى عصرى البطالمـة والرومان، عين للدراسـات والبحوث الإنسانية

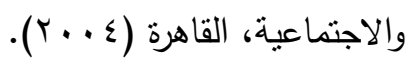

. سليم حسن: موسوعة مصر القديمة من عهد بطلميوس الخامس إلي نهاية عهد بطلميوس السابع،

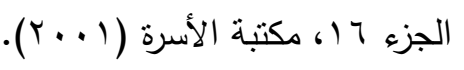

ـ فادية محمد أبو بكر : مصر زمن البطالمة، دار المعرفة الجامعية، الإسكندرية (T . . ץ).

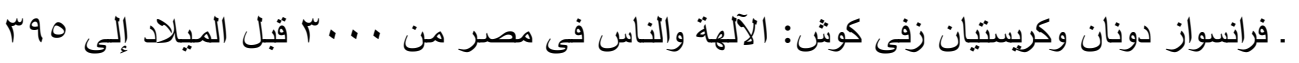

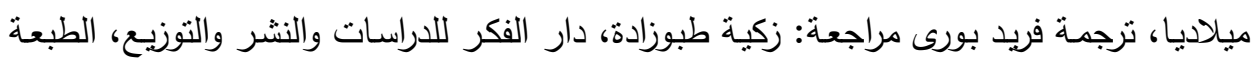

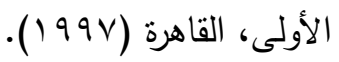

